\title{
Residual HIV-1 DNA Flap-independent nuclear import of CPPT/CTS double mutant viruses does not support spreading infection
}

\author{
Candela Iglesias ${ }^{1,2+}$, Mathieu Ringeard ${ }^{1,3+}$, Francesca Di Nunzio ${ }^{1}$, Juliette Fernandez ${ }^{1}$, Raphael Gaudin ${ }^{1,4}$, \\ Philippe Souque ${ }^{1}$, Pierre Charneau ${ }^{1 *}$ and Nathalie Arhel ${ }^{1 *}$
}

\begin{abstract}
Background: The human immunodeficiency virus type 1 (HIV-1) central DNA Flap is generated during reverse transcription as a result of $(+)$ strand initiation at the central polypurine tract (CPPT) and termination after a ca. 100 bp strand displacement at the central termination sequence (CTS). The central DNA Flap is a determinant of HIV-1 nuclear import, however, neither CPPT nor CTS mutations entirely abolish nuclear import and infection. Therefore, to determine whether or not the DNA Flap is essential for HIV-1 nuclear import, we generated double mutant (DM) viruses, combining CPPT and CTS mutations to abolish DNA Flap formation.
\end{abstract}

Results: The combination of CPPT and CTS mutations reduced the proportion of viruses forming the central DNA Flap at the end of reverse transcription and further decreased virus infectivity in one-cycle titration assays. The most affected DM viruses were unable to establish a spreading infection in the highly permissive MT4 cell line, nor in human primary peripheral blood mononuclear cells (PBMCs), indicating that the DNA Flap is required for virus replication. Surprisingly, we found that DM viruses still maintained residual nuclear import levels, amounting to 5$15 \%$ of wild-type virus, as assessed by viral DNA circle quantification. Alu-PCR quantification of integrated viral genome also indicated 5-10\% residual integration levels compared to wild-type virus.

Conclusion: This work establishes that the central DNA Flap is required for HIV-1 spreading infection but points to a residual DNA Flap independent nuclear import, whose functional significance remains unclear since it is not sufficient to support viral replication.

\section{Background}

During infection, the reverse transcriptase (RT) of retroviruses converts the $(+)$ strand RNA genome into double-stranded DNA prior to nuclear import. Similar to all DNA polymerases, the retroviral RT requires the 3' OH of a primer to initiate polymerisation. The primer used for (-) strand synthesis is a cellular tRNA already present in the retroviral particles prior to infection and anneals to the 5 ' region of the genome at the primer binding site (PBS). The primer used for $(+)$ strand synthesis is a polypurine tract (PPT) present in the 3' region of the RNA genome that resists RNase $\mathrm{H}$

\footnotetext{
* Correspondence: pierre.charneau@pasteur.fr; nathalie.arhel@pasteur.fr + Contributed equally

'Molecular Virology and Vaccinology Unit, Department of Virology, Institut Pasteur, Paris, France

Full list of author information is available at the end of the article
}

degradation concomitant with (-) strand synthesis. The genome of lentiviruses contains two such cis-acting purine-rich sequences: the 3'PPT common to all retroviruses and an additional central PPT present in the coding sequence of the integrase. The resulting initiation of $(+)$ strand synthesis at the cPPT as well as at the 3'PPT leads to a $(+)$ strand discontinuity at the centre of lentiviral genomes [1-5].

Similar to central $(+)$ strand initiation, the termination of reverse transcription is a further feature that distinguishes lentiviruses from other orthoretroviruses. For most retroviruses, termination occurs when the RT reaches the 5' end of the template. In the case of lentiviruses however, such as HIV-1 [6], EIAV [4], and FIV [5], reverse transcription terminates $c a .100 \mathrm{nt}$ downstream of the CPPT at stretches of $\mathrm{A}$ and $\mathrm{T}$ nucleotides (the central termination sequence, CTS) whose 
conformation disfavours binding to RT enzyme and thus halts reverse transcription. As a result of the cPPT and CTS cis-acting sequences, the final product of lentiviral reverse transcription contains a $c a .100$ nt overlap, or "DNA Flap", at the centre of the genome.

Mutations introduced either in the cPPT [7-9] or in the CTS [6] of HIV-1 lead to a loss of HIV-1 infectivity that is proportional to the number and positional impact of introduced mutations. The conversion of cPPT purines into pyrimidines compromises central initiation of (+) strand synthesis and thus central DNA Flap formation [7]. Similarly, the mutation of $\mathrm{dA}_{n}-\mathrm{dT}_{n}$ tracts in the CTS leads to aberrant (+) strand termination events spread over a distance of over 500 nt downstream of the cPPT [6]. Therefore, both the cPPT and CTS are required to form a functional central DNA Flap, and HIV-1 infection is impaired if either are mutated.

The defect in viral replication observed for cPPT mutant viruses $[7,10,11]$ is not accounted for by defects in viral DNA synthesis, integration, or virus production [9] but by a defect in nuclear import $[9,10,12]$. The importance of the central DNA Flap for nuclear import was harnessed by the gene therapy field when it was shown that re-insertion of the CPPT and CTS sequences in lentiviral vectors significantly enhanced gene transfer efficiencies by increasing nuclear import $[9,13]$. It is now systematically included in lentiviral vectors.

Interestingly, central (+) strand initiation has been shown to protect the HIV-1 genome from editing by cytidine deaminases of the APOBEC3 family downstream of the cPPT sequence [14]. Protection was high closest to the $\mathrm{CPPT}$ and decreased progressively further downstream. APOBEC3 enzymes edit exclusively singlestranded DNA, which in the case of HIV corresponds to the newly-synthesised (-) strand DNA. Editing is possible only until synthesis of the complementary $(+)$ strand. Therefore, sequences immediately downstream of $(+)$ strand initiation PPT sequences are more protected from editing than those upstream or further downstream $[14,15]$. It has been suggested that APOBEC3G/F editing wholly accounts for the infectivity defect of cPPT mutant HIV [16]. However, the benefit of the central DNA Flap is not contested in the context of HIV-1derived vectors, which are standardly produced in APOBEC3G-negative 293T cells [5,9,10,12,13,17-34]. Furthermore, in the case of CTS mutants, a (+) strand segment is correctly initiated at the cPPT [6] and should protect downstream sequences from deamination as in wildtype virus. Therefore, the observed strong replication defect of CTS mutants in Vif non-permissive cells [16] cannot be attributed to APOBEC3G restriction.

Nevertheless, the importance of the central DNA Flap for HIV-1 nuclear import, infectivity and replication in vivo has been a source of much debate over the past 10 years. Some papers have proposed that the central DNA Flap contributes minimally, if at all, to HIV-1 replication, although some degree of impairment for DNA Flap mutants is observed in human PBMCs and macrophages [16,35-38]. However, other studies claim that the central DNA Flap plays an important role in HIV nuclear import, infectivity, transduction efficiency, and viral replication [6,7,9-13,17-34,39]. Therefore, the debate seems really to reside in whether the central DNA Flap is essential for infection and replication, or whether it merely contributes towards rendering these more efficient.

Mutations in the cPPT do not lead to totally noninfectious viruses [6,7] and some residual HIV-1 nuclear import is observed [10], suggesting either that viruses may enter the nucleus in a DNA-Flap-independent manner or that the mutations introduced in the CPPT are not sufficient to abolish DNA Flap formation. Unfortunately, the extent of mutations that can be introduced in the CPPT is limited by the need to maintain a functional integrase. The $225 \mathrm{~T}$ mutant [17], which contains 6 synonymous mutations, maintains residual infectivity probably because the CPPT is only partially inactivated. To more profoundly disrupt DNA Flap formation, the CPPT-D mutant was generated to contain an additional $\mathrm{K} \rightarrow \mathrm{R}$ amino acid change and compared with a control virus $\mathrm{CPPT}-\mathrm{AG}$ containing the same $\mathrm{K} \rightarrow \mathrm{R}$ mutation, but maintaining the polypurine nature of the cPPT [9]. Despite non-detectable (+) strand discontinuity, the cPPT-D mutant still retained residual infectivity and nuclear import (5-10\% of wild-type HIV-1) [9]. Therefore, it remains an open question whether observed residual infection is due to only partial disruption of the DNA Flap, or whether a DNA-Flap-independent nuclear import exists in ca. $10 \%$ of infectious events. Since we cannot introduce any further mutations in the cPPT, we set out to combine CPPT mutations with the previously described CTS mutant that leads to aberrant $(+)$ strand termination [6], on the premise that residual central strand initiation will then not lead to functional DNA Flap formation. We thus report the generation of fully disruptive mutants for DNA Flap formation that preserve integrase function, and document their effect on nuclear import, infectivity and replication.

\section{Results}

\section{Production of wild-type and mutant viruses}

In HIV-1, the cPPT sequence is an exact copy of the 3'PPT and is composed sequentially of a T-box, two Aboxes and a G-box (Figure 1). We previously found that the two A-boxes have the most profound impact on HIV-1 infectivity when mutated, followed in importance by the G- and lastly the T-box (P. Charneau, unpublished data). The 223 mutant, which introduces two 


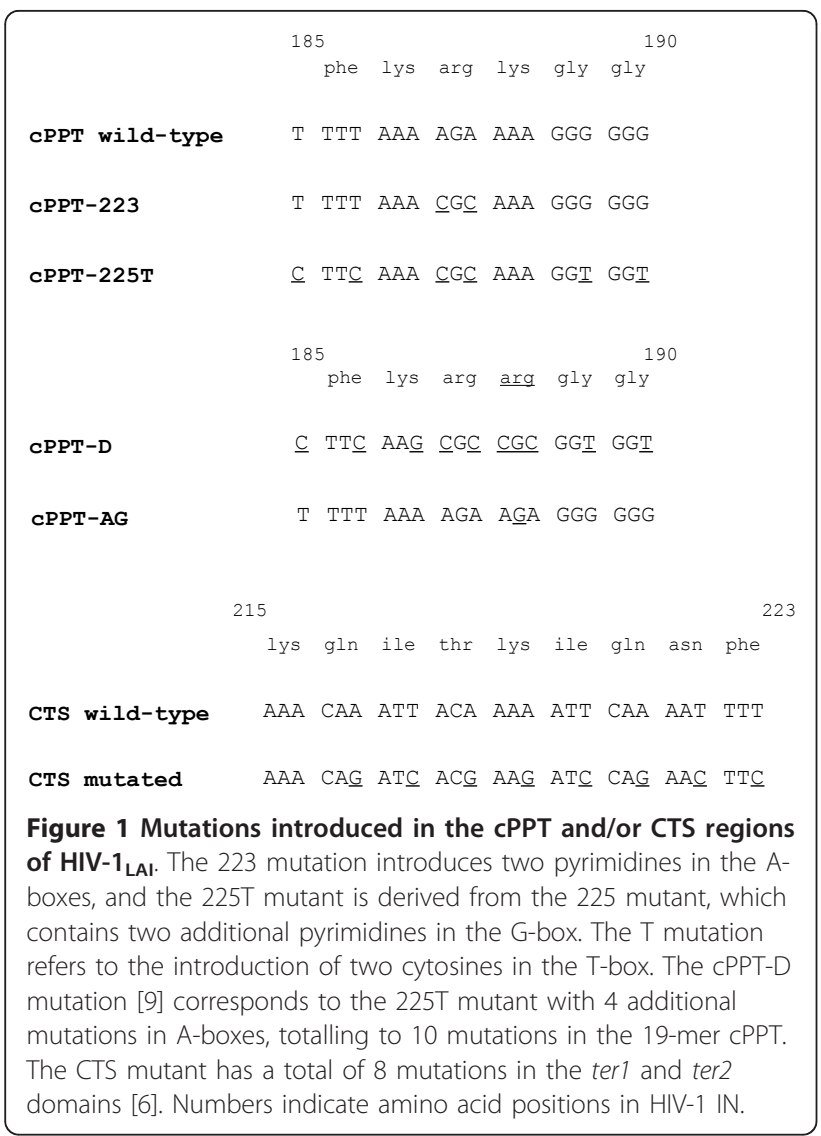

pyrimidines in the A-boxes, is one of the least affected mutants [7]. The 225T mutant combines mutations in all four boxes and is the most affected amongst the synonymous cPPT mutants [17]. The addition of a single non-synonymous mutation (cPPT-D mutant) has the most profound effect on viral replication [9]. Although this mutant introduces an amino acid change at position 188 of the integrase coding region (K188R), the control virus (cPPT-AG) with the same amino acid change behaved like wild-type virus in terms of virus production and viral DNA synthesis [9]. Position 188 of integrase (IN) is important for salt bridge formation between the catalytic core and the N-terminal domain, however, the presence of an arginine rather than a lysine at this position is naturally found in HIV-2 IN and does not perturb salt bridge formation [40]. The previously described CTS mutant, which was designed to disrupt the $\mathrm{dA}_{n}$ $\mathrm{dT}_{n}$ tracts of the CTS while respecting the corresponding integrase amino acid sequence, results in DNA Flaps of abnormal length and severely impairs infectivity [6].

We generated double mutants (DM) by combining in HIV-1 $1_{\text {LAI }}$ and HIV-1 $1_{\text {LAI }} \Delta$ env-vsvG viruses, the 223 , $225 \mathrm{~T}$ or cPPT-D cPPT mutants with the previously described CTS mutation [6]. There were no appreciable differences in virus p24 concentration between the wild- type virus and any of the mutant viruses (Additional File 1 Figure S1), confirming that DNA Flap mutations do not affect virus production [9].

\section{Impact of DNA Flap mutations in single-cycle infectivity}

We first tested the single and double mutant viruses for infectivity in single cycle infections in the P4-CCR5 reporter cell line, which are HeLa CD4+ CXCR4+ CCR5 + carrying the Lac $\mathrm{Z}$ gene under the control of the HIV-1 LTR promoter [6]. CPPT and CTS HIV-1 mutants exhibited an impairment of infection that was significant and increasingly important with increasing number of mutations (Figure 2A). Reduction was consistent and was of 2-, 14-, 16- and 20-fold for 223, CTS, cPPT-D and 225T, respectively, compared to wild-type virus (Figure 2B). The combination of CPPT and CTS mutations increased this defect significantly in the case of the DM-223 and DM-D mutants. The DM-D mutant was the most affected of all DNA Flap mutants and only retained a very residual infectivity of $0.8+/-0.3 \%$ of wild-type virus (Figure 2B). The pseudotyping of HIV-1 with the vesicular stomatitis virus glycoprotein (VSV-G), which confers broad tropism and increases infectivity by 10-fold, attenuated the infectivity defects observed with wild-type envelope HIV-1 $1_{\text {LAI }}$ viruses (Figure $2 \mathrm{C}$ ). The average reduction in infectivity was between 2 - and 5fold for all single mutants. However, the combining of cPPT and CTS mutations significantly further decreased the infectivity of pseudotyped viruses. The most affected mutant, DM-D VSV-G, retained an infectivity of $9.4+/-$ $0.9 \%$ of wild-type virus (Figure $2 \mathrm{D}$ ).

Taken together, these results indicate that all cPPT single and double mutants are severely impaired in infectivity, but that the most disrupted mutant still maintains residual infection (ca. $1 \%$ for non-pseudotyped viruses and $c a$. $10 \%$ for VSV-G pseudotyped viruses) in a one-round titration assay.

It has recently been reported that central DNA Flap mutant HI-viruses maintain wild-type infectivity in single cycle infection assays following production in APOBEC3G-negative 293T cells [16]. To test the possibility that the apparent discrepancy between our results and those reported by Hu et al. 2010 [16] might reflect differences between virus strains or the production proto$\mathrm{col}$, the molecular clones used in $\mathrm{Hu}$ et al. were obtained from E. Poeschla (Mayo Clinic). The ability of these viruses to infect P4-CCR5 indicator cells was tested in parallel with our wild-type virus and DNA Flap mutants. The mutants from both studies displayed a comparable infectivity defect (up to 10-fold) at all multiplicities of infection tested (Figure 2E).

To test the possibility that the discrepancies between our results and those from $\mathrm{Hu}$ et al. might result from the use of different indicator cell lines, the GHOST3 
A

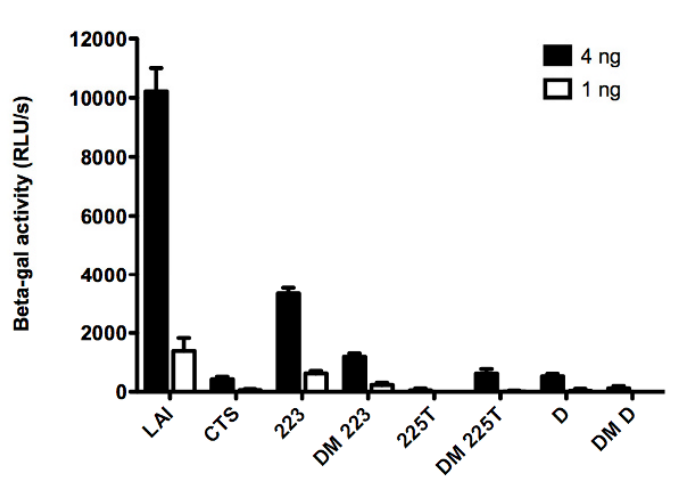

C

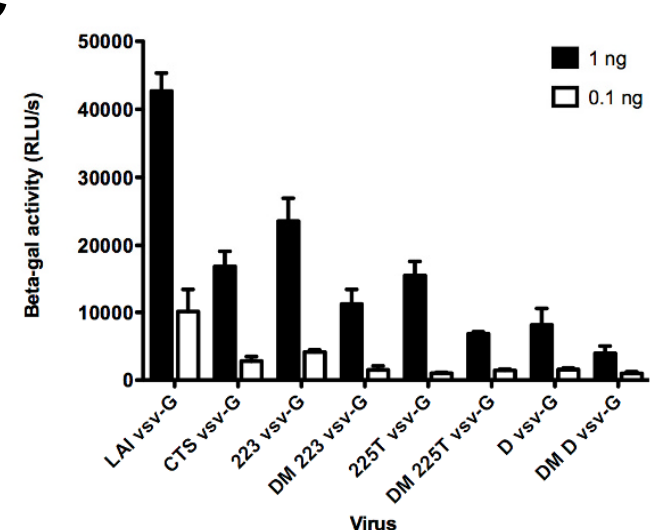

E

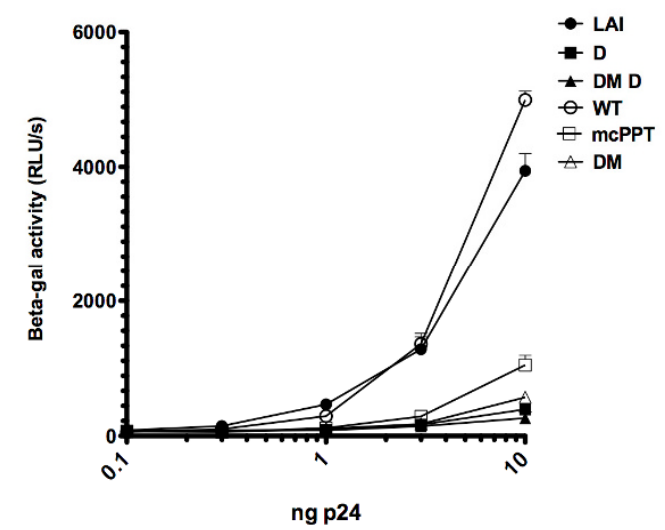

B

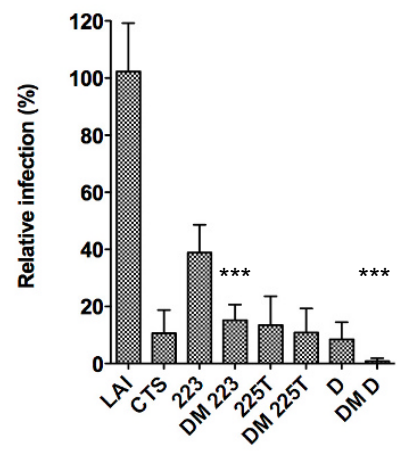

$\mathrm{D}$

Virus

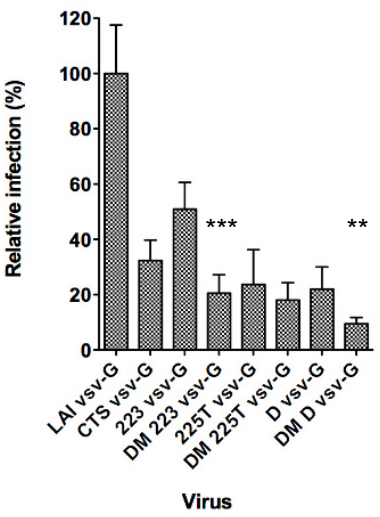

F

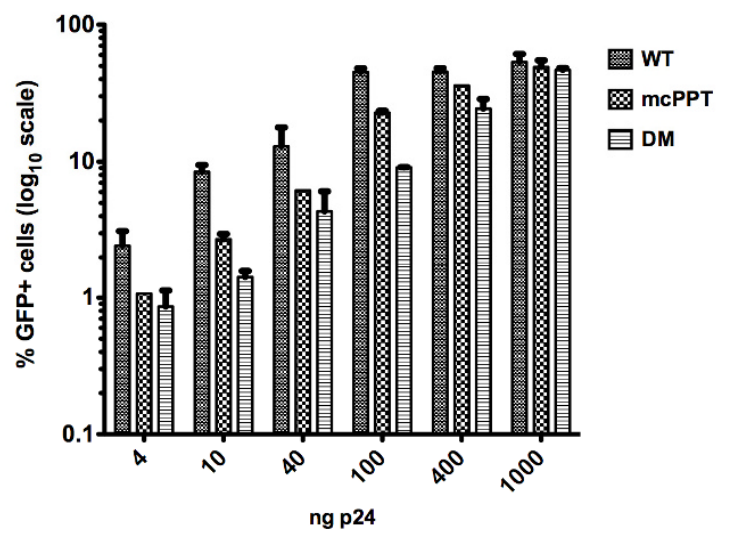

Figure 2 Single-cycle titration assay in P4-CCR5 cells indicate an increased infectivity defect of DNA Flap double mutant viruses compared with CPPT or CTS single mutants. (A) P4-CCR5 cells were infected with 4 ng or $1 \mathrm{ng}$ p24 of HIV-1 wild-type envelope and infectivity was measured $48 \mathrm{~h}$ p.i by tat transactivation of the beta-gal promoter (mean of triplicates +/- SD representative of two independent experiments). (B) Relative infection of the DNA Flap mutant viruses compared with wild-type LAl virus (mean of three independent experiments carried out in triplicate over a range of viral concentrations $+/-\mathrm{SD}$ ). Statistical relevance was calculated using paired t test to compare CPPT single mutant viruses with their corresponding DM virus, ${ }^{* * *} p<0.001$. (C) P4-CCR5 cells were infected with 1 ng or 0.1 ng p24 of HIV-1 VSV-G and infectivity was measured $48 \mathrm{~h}$ p.i by Tat transactivation of the beta-gal promoter (mean of triplicates $+/$ - SD representative of three independent experiments). (D) Relative infection of the DNA Flap mutant viruses compared with wild-type LAl virus (mean of three independent experiments carried out in triplicate +/- SD). Statistical relevance was calculated using paired t test to compare CPPT single mutant viruses with their corresponding DM virus, ${ }^{* * *} \mathrm{p}<0.001$. (E) P4-CCR5 cells were infected with wild-type env NL4-3 viruses from the Hu et al., 2010 study (WT, mcPPT, DM) in parallel with our wild-type and mutant LAI viruses (LAI, D, DM D). Results show the mean beta-galactosidase activity of duplicates +/- SD and are representative of three independent experiments. (F) GHOST3 cells were infected with increasing doses of viruses from the Hu et al. study [16]. Infectivity was assessed at $48 \mathrm{~h}$ p.i using flow cytometry. Results show the mean percentage of GFP positive cells of three independent experiments. 
cells used in the $\mathrm{Hu}$ et al. study were obtained also from E. Poeschla and infected in parallel with molecular clones from $\mathrm{Hu}$ et al. and our wild-type and mutant viruses (Figure 2F and Additional File 2 Figure S2). GHOST3 cells are HOS CD4+ CXCR4+ CCR5+ carrying the green fluorescent protein (GFP) gene under the control of the HIV-2 LTR promoter. This reporter cell line has the advantage that it does not require cell lysis or addition of substrate, and allows for percentages of infected cells to be measured. We note however that percentages of infected cells have a reduced dynamic range $(0-100 \%$, Figure $2 \mathrm{~F})$, compared with RLU values from P4-CCR5 cells (4-5 $\log _{10}$, Figure $2 \mathrm{~A}, \mathrm{C}$ ), and do not distinguish single from multiple integration events. The percentage of infected cells was consistently less for DNA Flap mutants compared with wild-type virus (up to 6-fold), but the amplitude of the infectivity defect was reduced or lost at high multiplicities of infection (Figure $2 \mathrm{~F})$, where multiple integration events occur. The narrow linear dynamic range of GHOST3 cells may account for the diverging results reported by $\mathrm{Hu}$ et al. [16].

\section{Impact of DNA Flap mutations on viral replication}

Single cycle infection assays are sensitive to very low infectivity and successful integration events as measured by beta-gal activity, but do not guarantee that the viruses can establish a spreading infection in cell culture. We therefore carried out kinetics of replication following infection with wild-type envelope HIV-1. MT4 cells were chosen because they are highly permissible to HIV-1, allowing rapid and efficient replication. MT4 cells are APOBEC3G-negative, and therefore the role of central (+) strand initiation in protecting the genome from editing $[14,16]$ is not a confounding factor in this assay. In 2 independent experiments, the replication of wild-type HIV-1 $1_{\text {LAI }}$ peaked at 5-6 days post infection; in contrast, the replication of 223, 225T, CTS and cPPT-D single mutants was delayed on average by 3, 5, 6 and 9 days, respectively, compared with wild-type HIV-1 $1_{\mathrm{LAI}}$ (Figure 3). While DM-223 showed a delay similar to that of the CTS mutant, virus replication remained undetectable for DM-225T and DM-D mutants over the 24-day period, indicating that despite minimal singlecycle infection, these viruses do not replicate in the time frame of the assay.

To verify that the observed replication defect is not cell-dependent, we also tested the ability of doublemutant viruses to establish spreading infection in human primary PBMCs from two healthy donors, which were infected with 0.1 and $1 \mathrm{ng}$ p 24 of wild-type and double mutant viruses. The replication of wild-type $\mathrm{HIV}_{\text {LAI }}$ peaked at 7-10 days post-infection (Figure 4). In contrast, no peak of replication was detected for double mutant viruses over the 40-day period, and virus
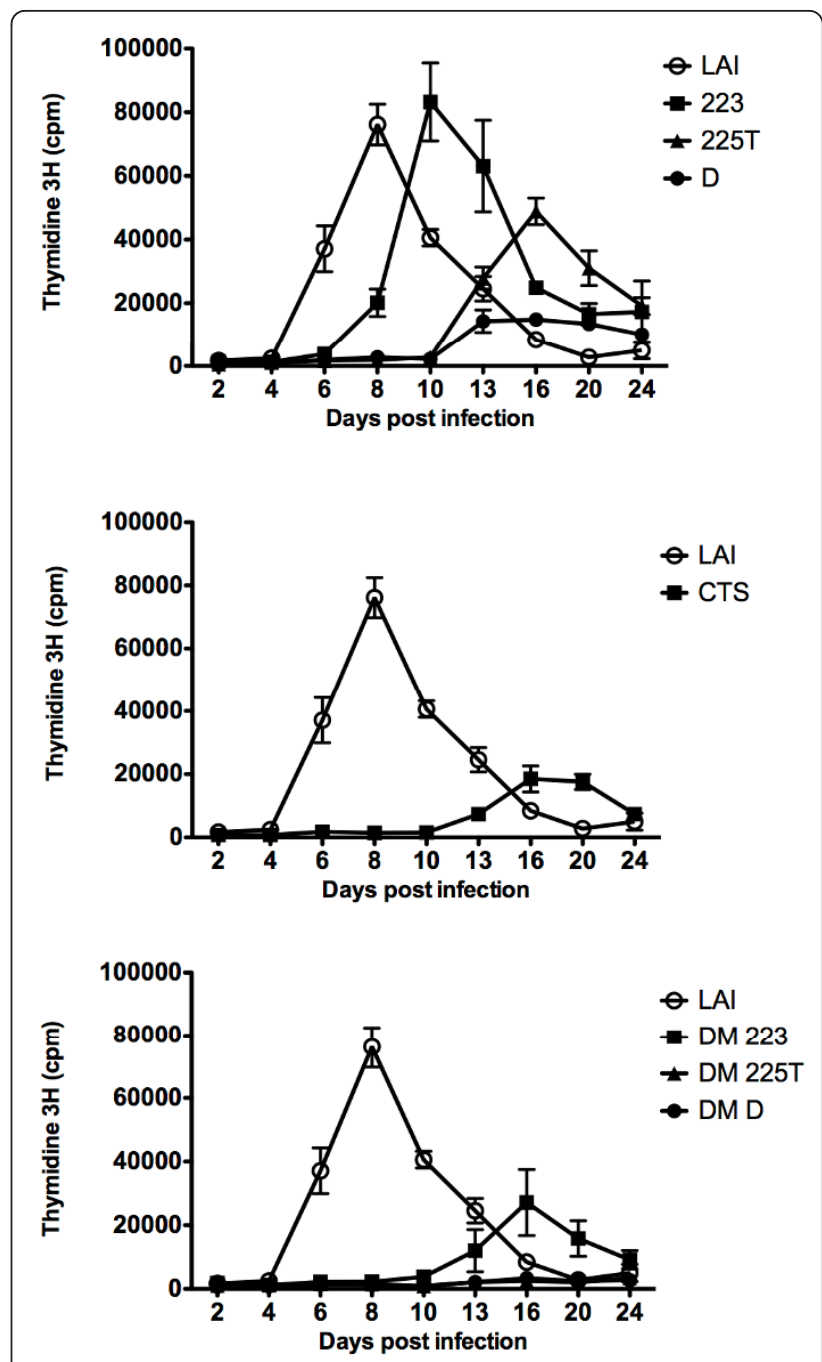

Figure 3 Replication kinetics in MT4 cells indicate an increased replication defect of DNA Flap double mutant viruses compared with cPPT or CTS single mutants. MT4 cells were infected with $1 \mathrm{ng}$ p24 of wild-type envelope HIV-1 and virus production was measured at given time points post-infection by performing RT assay on the culture supernatants. Results show the mean of triplicates +/- SEM and are representative of two independent experiments.

concentration was only sporadically measurable above the assay minimum detectable limit (ca. $3 \mathrm{ng} / \mathrm{ml})$. The fact that DM 223, which replicated in MT4 cells despite some delay compared to wild-type virus (Figure 3), did not establish spreading infection in PBMCs confirms the high permissiveness of MT4 cells. Moreover, although viruses used for this study were wild-type for Vif, the stronger block in replication observed in PBMCs may also reflect the increased sensitivity of DNA Flap mutants to APOBEC3G/F-mediated deamination in PBMCs $[14,16]$. We conclude that DNA Flap double mutant viruses cannot establish spreading infection in 


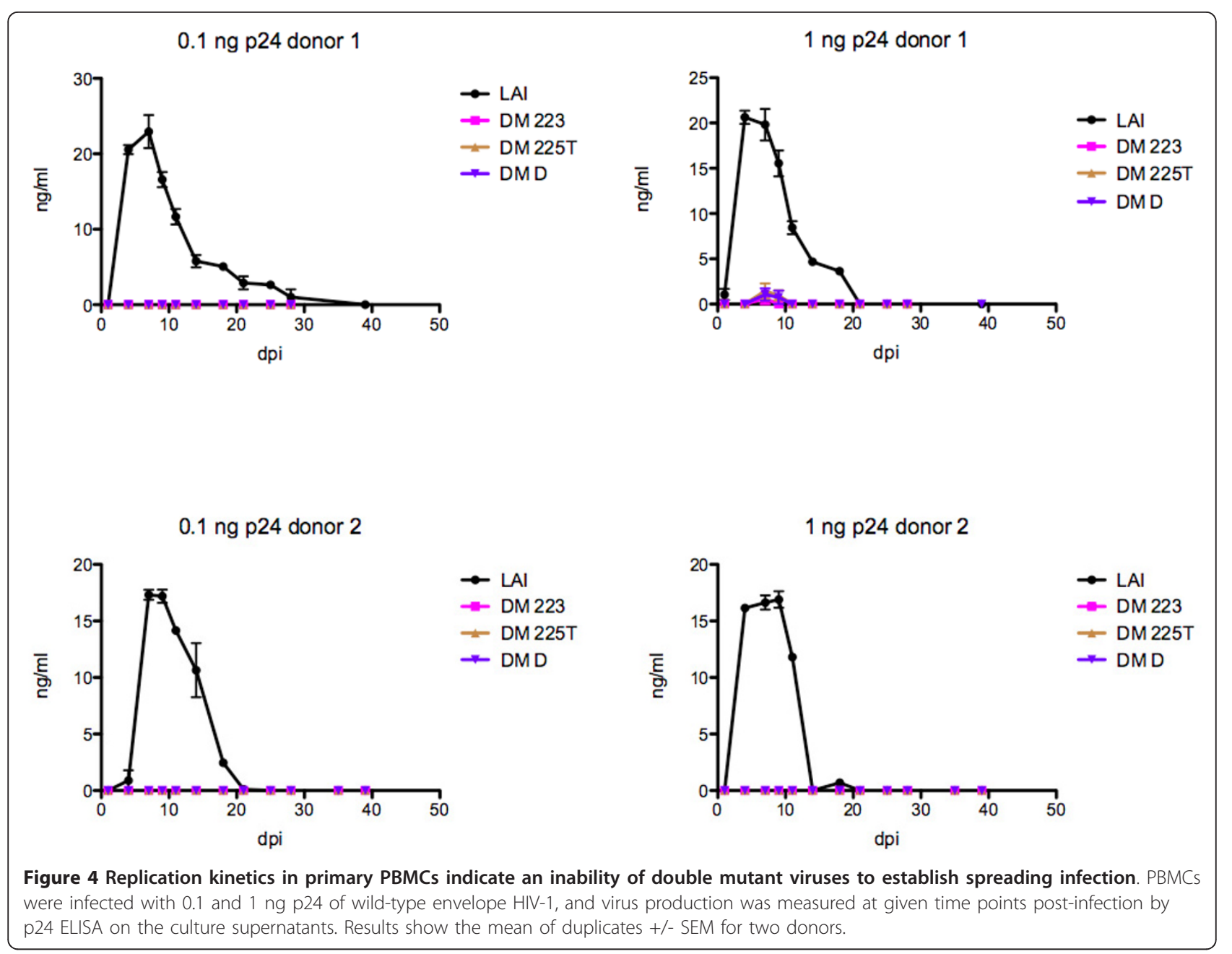

lymphocytic cell cultures despite detectable levels of infectivity in single cycle infection assays.

\section{Impact of DNA Flap mutations on nuclear import}

Once reverse transcribed in the cytoplasm, the HIV-1 linear DNA is imported into the nucleus where it either integrates or circularises. Circular forms of non-integrated viral DNA contain one or two long terminal repeats (LTR) and are thought to be dead-end products of infection. Since they are found exclusively in the nucleus of infected cells, they constitute convenient markers of nuclear import. We therefore used quantitative PCR to measure two-LTR DNA circles [41] in P4CCR5 cells infected with wild-type, single and double mutant HIV $_{\text {LAI }}$ vsvG viruses. At 24 h post-infection, quantification of 2-LTR junctions revealed a reduction in 2-LTR copy numbers of 3-6-fold for all single and double DNA Flap mutants compared to wild-type virus, indicating a defect in nuclear import (Figure 5A). As previously observed (P. Charneau, unpublished data), the CTS mutant has a nuclear import defect comparable to cPPT mutants. Mutations in the cPPT lead to linear DNA lacking the central DNA Flap while mutations in the CTS lead to linear DNA containing an aberrantly sized DNA Flap. Since both DNA Flap mutant types have impaired nuclear import, it is the integrity of the DNA Flap structure, rather the presence or not of a (+) strand discontinuity, that accounts for nuclear import. Furthermore, DNA Flap mutant viruses maintained a defect in 2-LTR copy numbers over a $72 \mathrm{~h}$ time course (Figure 5B), indicating an overall defect in nuclear import rather than a delay. D vsv-G and DM-D vsv-G viruses remained strongly defective for nuclear import throughout the time course (Figure 5B). Similar to results obtained from infectivity experiments (Figure 2), the combination of $\mathrm{CPPT}$ and CTS mutants led to a further decrease in 2-LTR copy numbers compared with single mutants. Using this test, DM-225T and DM-D maintain residual levels of 2-LTR circles of $10-20 \%$ of wild-type virus, indicating that disruption of the central DNA Flap severely impairs but does not abrogate nuclear import. 


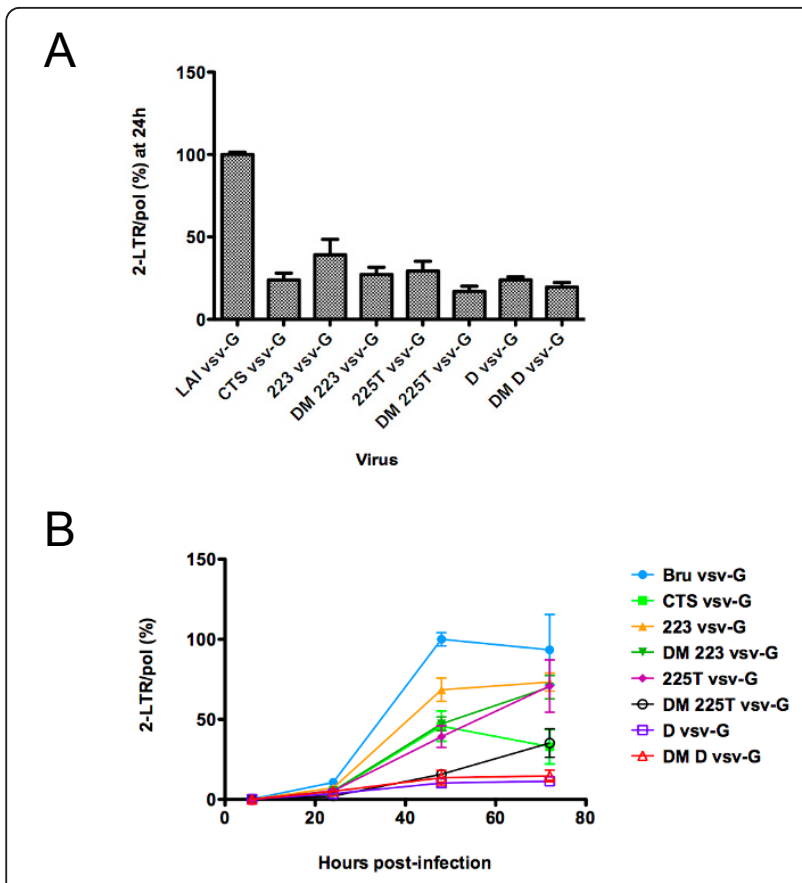

Figure 5 Quantification of 2-LTR circles and total HIV-1 DNA (Pol) by quantitative PCR shows defects in nuclear import for all DNA Flap mutants. P4-CCR5 cells were infected with wild-type and DNA Flap mutant viruses pseudotyped with VSV-G envelope. (A) Results show the number of 2-LTR circles normalised for pol copy numbers at $24 \mathrm{~h}$ post-infection. Non-infected samples did not give rise to amplified products. Cells infected in the presence of Nevirapine served as controls for each virus infection $\left(<10^{3}\right.$ copies for all samples) and were subtracted from each value. Values are represented as a percentage of wild-type and are the mean of 3 independent experiments carried out in duplicate +/- SEM. (B) Results show 2-LTR circles at given time points post-infection, normalised for pol copy number at $24 \mathrm{~h}$ post-infection. Values are represented as a percentage of wild-type at $48 \mathrm{~h}$ post-infection and are the mean of 2 independent experiments carried out in duplicate +/- SEM.

Two-LTR circles represent only a minute fraction of HIV-1 DNA in infected cells $(<1 \%$ of nuclear viral DNA), and small variations in their levels will lead to important changes in inferred nuclear import levels. One-LTR circles are more abundant (ca. $35 \%$ of nuclear viral DNA) [9], but cannot be distinguished by quantitative PCR. We therefore used restriction enzyme analysis coupled to Southern blotting to detect total, linear nonintegrated, and circularised forms of HIV-1 DNA in MT4 cells [9]. In three independent experiments, we found that at $48 \mathrm{~h}$ post-infection with wild-type HIV$1_{\text {LAI }}$, under $1 \%$ of viral DNA was in the form of 2-LTR circles, $35-45 \%$ as 1 -LTR circles, and $10-15 \%$ as linear unintegrated DNA (Figure 6A), which is concordant with previous work [9]. Linear viral DNA molecules undergo rapid integration or circularisation soon after entry in the nucleus [42-45]; therefore, measured linear
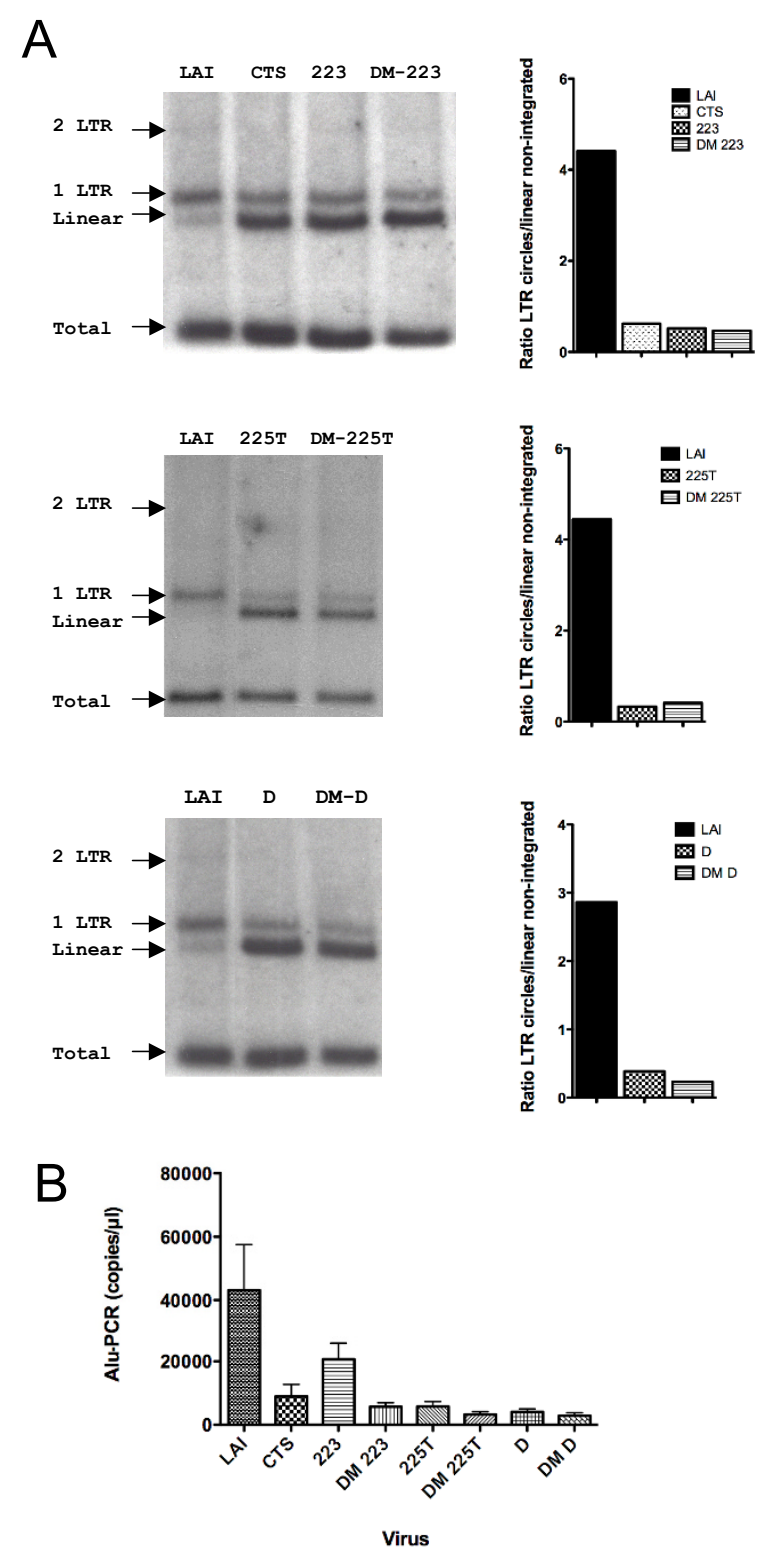

Figure 6 Quantification of LTR circles, linear unintegrated, and integrated HIV-1 DNA by Southern blotting and Alu-PCR confirms defects in nuclear import for all DNA Flap mutants. (A) MT4 cells were infected with wild-type or DNA Flap mutant viruses pseudotyped with VSV-G envelope. Total DNA was isolated $48 \mathrm{~h}$ post-infection and intracellular viral DNA forms were analysed by Southern blotting. Bands were quantified using Phosphorimager and nuclear import was assessed by plotting the ratio of LTR circles (nuclear) to linear non-integrated HIV-1 (predominantly cytoplasmic). (B) Assessment of HIV-1 integration by Alu-PCR. The graph shows mean values of 3 independent experiments +/- SEM.

DNA corresponds predominantly to cytoplasmic viral DNA, and its accumulation is indicative of a nuclear import defect. The ratio of 1- and 2-LTR forms over linear cytoplasmic viral DNA at $48 \mathrm{~h}$ post-infection, which was of 4 on average for wild-type HIV-1, was reduced, 
in the case of mutations in the cPPT, to $0.2-0.6$ indicating a nuclear import defect (Figure 6A). Using this Southern blot assay, we did not notice an additional impairment of nuclear import for DM viruses. Furthermore, despite the reduction in nuclear import, nuclear forms of viral DNA (1-LTR) could still be detected for both single and double DNA Flap mutants, confirming the residual level of nuclear import obtained with 2LTR quantitative PCR.

While these findings suggested that a residual proportion of viral pre-integration complexes might enter the nucleus in the absence of the central DNA Flap, we could not exclude that a small proportion of DNA circles form independently of nuclear import, through auto-integration events in the cytoplasm for instance [45]. To verify this, we quantified integrated viral DNA using Alu-PCR. If viral DNA circularisation occurs independently of HIV-1 nuclear import or at the expense of HIV-1 integration, which is essential for productive infection, integrated viral DNA would not be detected following infection with DNA Flap mutant viruses. We found that CPPT and CTS mutations led to significant reduction in detected integrated HIV-1 genome and that the combination of CPPT and CTS mutations in double mutants led to even greater defects in integration (Figure 6B). The integration defect for the 223 mutant was only 2 -fold, which is concordant with the single cycle infectivity and quantitative PCR of 2-LTR circles data (Figure 2). Importantly, integrated signal could be detected for all viruses, including the most disrupted DM-D virus, equivalent to 5-10\% of wild-type levels, consistent with the result that all mutant viruses have some residual nuclear import.

Taken together, our data indicate that all DNA Flap mutants analysed have a strongly impaired nuclear import, but maintain a residual level of nuclear import which amounts to $5-15 \%$ of wild-type HIV-1, depending on the assay used. The mechanism for this DNA-Flapindependent nuclear import is unknown. The proportion of circularised and integrated HIV-1 following nuclear import is similar to that observed for wild-type virus. However, levels of integrated virus are insufficient to establish spreading infection.

\section{Discussion}

The central DNA Flap is an important determinant of HIV-1 nuclear import, but previously described cPPT mutants still maintain minimal nuclear import (of $c a$. $10 \%$ of wild-type virus) resulting in residual infection in single-cycle titrations. The previous lack of sufficiently disruptive CPPT mutants has prevented us from concluding whether these residual levels are due to incomplete disruption of the DNA Flap or whether they point to a DNA-Flap-independent nuclear import. In this study, we combined cPPT and CTS mutations to ensure that possible $(+)$ strand central initiation in $10 \%$ of cPPT mutant viruses will not lead to the formation of functional DNA Flap. We found that the most affected double mutants were unable to establish spreading infection in the highly permissive MT4 cells, indicating that the DNA Flap is required for virus replication. Surprisingly, all DNA Flap mutants, including the most disrupted, maintained residual nuclear import levels amounting to $5-15 \%$ of wild-type levels.

Our results reveal an apparent discrepancy between the detected residual nuclear import and the absence of spreading infection in lymphocytic cells. A residual proportion of viral pre-integration complexes might enter the nucleus in the absence of the central DNA Flap, but poor efficiency, low numbers or sub-optimal integration may be detrimental for viral replication. It has been suggested that APOBEC editing wholly accounts for the infectivity defect of cPPT mutant HIV [16]. While we cannot exclude a minor contribution of APOBEC editing to the phenotypes we observe, it cannot entirely contribute to the replication defect of DNA Flap mutant viruses since the most defective DNA Flap mutants were unable to establish spreading infection in MT4 cells, which are APOBEC3G-negative.

\section{The DNA Flap controversy}

The central DNA Flap and its importance for HIV-1 replication have been controversial for many years. Its role as a cis-acting determinant of nuclear import has proven all-important for gene transfer based on lentiviral vectors and in the context of replicative viruses [5,9-13,17-21,23,24,26-31,33,34,39]. This defect is independent of envelope tropism (R5, X4, VSV-G) or cell type used (cell lines, primary lymphocytes, APOBEC3G/ F status). Still, a certain element of contention remains regarding the extent of the DNA Flap's importance, with some reports contesting its role in nuclear import and replication [16,35-38].

We believe this controversy may be resolved by considering two points. Firstly, the benefit to infection/ transduction brought by the central DNA Flap will be overseen in saturating experimental conditions with assays that cannot distinguish single from multiple infectious events per cell. Concordantly, high MOIs in the context of lentiviral transductions attenuate defects measured in the absence of the central DNA Flap [11]. Similarly, this paper shows that the infectivity defect of DNA Flap mutants is more apparent for wild-type envelope HIV-1 than for VSV-G pseudotyped HIV-1, which is 10-fold more infectious; and more apparent in PBMCs than MT4 cells, which are highly permissive. In transduction experiments using HIV-1 derived vectors coding for eGFP, the benefit of the DNA Flap in terms 
of the percentage of transduced cells will also decrease with increasing MOI, with transduction efficiencies that can reach $100 \%$ for both Flap+ and Flap- vectors in permissive cells (Figure 7). The same loss of a differential phenotype at high and low MOI was also observed following infection of GHOST cells with the viruses from the $\mathrm{Hu}$ et al., 2010 study (Figure 2F). In contrast, the difference in mean fluorescent intensity (MFI), which reflects cumulative nuclear entry events, will increase (Figure 7). Therefore, in the case of multiple infectious events per cell, the true impact of the central DNA Flap may only be reliably assessed by combining both percentage of infected cells and MFI [31].

Secondly, DNA Flap mutant viruses display an equal nuclear import defect in both dividing and non-dividing cells $[9,10,39,46]$. Therefore, assays that compare cycling cells with aphidicolin-arrested cells will invariably see no difference in terms of nuclear import and infectivity of DNA Flap mutant viruses. These experiments are based on the hypothesis that HIV-1 passes through the nuclear
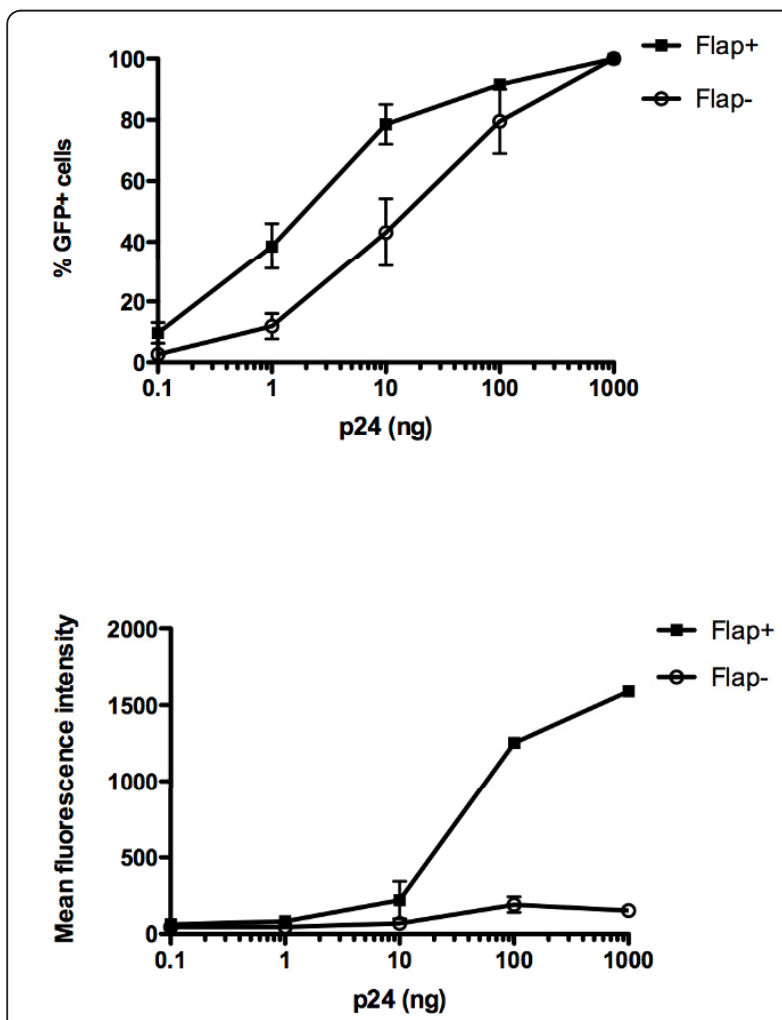

Figure 7 Effect of the central DNA Flap on percentage of transduced cells and mean fluorescent intensity upon increasing MOI. HeLa cells were transduced with Flap+ or FlapHIV-derived vectors (TRIP-eGFP and HR-eGFP, respectively) [9] in 6well plates with $0.1,1,10,100$ or $1000 \mathrm{ng} / 0.3 \times 10^{6}$ cells. The percentage of GFP-positive cells and the mean fluorescent intensity were assessed $48 \mathrm{~h}$ post-transduction by flow cytometry (BD Calibur). pore in non-dividing cells, but uses an alternative route for nuclear entry during mitosis. However, several arguments suggest that this might not be the case. (1) A mitosis-independent nuclear import in cycling cells has been reported [47]. (2) A genome-wide RNA interference-based screen comparing HIV-1 and MLV infections identified unique nuclear import factors for HIV-1 even though the study was carried out in cycling cells [48]. (3) The assumption that HIV-1 might passively gain access to the chromatin upon mitosis, if based on the belief that cytoplasmic and nuclear contents mix homogeneously throughout mitosis, is not valid. Indeed, evidence suggests that mitotic cells maintain spatial information through gradients, such as the RanGTP gradient that surrounds chromatin [49,50]. (4) HIV-1 mutants with a nuclear import defect in cell cyclearrested cells often maintain this defect in cycling cells $[9,10,39,46,51]$. (5) The replication of certain lentiviruses (such as EIAV, CAEV and VISNA) is entirely limited to macrophages, which do not divide.

\section{Mechanism of DNA-Flap-dependent nuclear import}

We have previously shown that the central DNA Flap mediates nuclear import by promoting viral capsid uncoating at the nuclear pore [17]. However, the molecular mechanisms underlying DNA-Flap-dependent maturation of HIV-1 capsids remain unknown. Since DNA-Flap-dependent uncoating can be reconstituted in vitro in purified vector particles undergoing endogenous reverse transcription, it is not likely that any cellular component(s) is implicated in the uncoating process unless it is already present in the particle. One possible hypothesis is that formation of the central DNA Flap at the end of reverse transcription triggers major morphological rearrangements that lead to the release of the HIV-1 pre-integration complex from the capsid core. Intriguingly, CTS mutations, which lead to DNA Flap structures with aberrant length spread over a distance of $500 \mathrm{nt}$ downstream of the CPPT [6], severely impair nuclear import and infectivity. These data suggest that a central DNA Flap of aberrant length is as detrimental to viral replication as is the absence of the central DNA Flap.

\section{Mechanism of DNA-Flap-independent nuclear import} The mechanism for the DNA-Flap-independent nuclear import uncovered by this study is unknown, but evidence suggests that it might involve at least some of the same host factors as DNA-Flap dependent nuclear import since Flap-negative viruses are as sensitive to the depletion of TNPO3 or Nup153 as wild-type virus $[52,53]$. DNA Flap-independent nuclear import cannot be due to viral complexes entering the nucleus via an alternative route during mitosis, since the DNA-Flap- 
independent nuclear import reported here may be observed in both cycling and non-cycling cells $[9,10,39,46]$. We have noted that smaller lentiviral genomes, such as minimal HIV-1 derived vectors, have a higher proportion of DNA-Flap-independent nuclear import (P. Charneau, unpublished data), suggesting that the smaller the viral genome, the less dependent it is on the central DNA Flap for passage through the nuclear pore.

Taken together, our data establish that the integrity of the central DNA Flap is required to support a spreading infection and confirm that all CPPT and CTS mutants have a nuclear import defect. Although this defect may vary in its amplitude depending on the nuclear import assay and the MOI used, it is consistently observed. Of note, central $(+)$ strand initiation may also carry further benefits for HIV-1 replication besides assisting viral nuclear import, such as protection from APOBEC3G/F editing as previously shown $[14,16]$. Here, we show that even the most disrupted DNA Flap mutants still maintain residual nuclear import, but that this does not support spreading infection in human lymphocytic cells. It will be interesting to determine the mechanisms for this DNA Flap-independent nuclear import.

\section{Methods}

\section{Cells and viruses}

The P4-CCR5 reporter cells are HeLa CD4+ CXCR4+ CCR5+ carrying the Lac $\mathrm{Z}$ gene under the control of the HIV-1 LTR promoter [6]. MT4 cells are HTLV-1 transformed human CD4+ T cells that allow acute cytopathic HIV-1 infection [54]. The 293T cells are human embryonic kidney cells. Citrate human blood was obtained from healthy donors (Etablissement Français du Sang) and PBMCs were isolated following Ficoll gradient. GHOST3 cells are HOS CD4+ CXCR4+ CCR5+ carrying the green fluorescent protein (GFP) gene under the control of the HIV-2 LTR promoter.

The viral molecular clone used in our study was HIV$1_{\text {BRU }}$ also called LAV (Lymphadenopathy-associated virus), based on the 1983 isolate from a homosexual patient with lymphadenopathy [55]. This molecular clone is HIV-1 $1_{\mathrm{LAI}}$ for all intents and purposes and is referred to as such in the manuscript. In the case of pseudotyping with VSV-G, we used a $\Delta$ env molecular clone that was generated by deletion of the $1.3 \mathrm{~kb} \mathrm{KpnI-}$ BglII fragment in HIV-1 env [56]. Molecular clones from the $\mathrm{Hu}$ et al., 2010 study are NL4-3 Vpr-, WT, mcPPT (cPPT mutant) or DM (cPPT and CTS double mutant).

The generation of 223 [7], 225T [17], cPPT-D [9] and CTS [6] mutants by site directed mutagenesis has been described previously. Double mutants were generated by splice overlap extension PCR using the following primers to amplify the cPPT region, DM1 5'-ACATACAGACAATGGCAG-3' and DM2 5'-TGCTATTATGT CTACTATTC-3' and the following primers to amplify the CTS region, DM3 5'-ATAGTAGACATAATAGCAAC-3' and DM4 5'-TATGTCGACACCCAATTC-3'.

\section{Virus production}

Viruses were produced by transient transfection of 293T cells using calcium phosphate co-precipitation with the wild-type or mutant proviral plasmids based on pLAI or pNL43 Vpr-. In the case of pseudotyping with VSV-G, pLAI $\Delta$ env was co-transfected with the VSV-G envelope expression plasmid pHCMV-G [57]. Virus concentration in supernatants was measured by p24 ELISA according to the manufacturer's instructions (Perkin Elmer).

\section{Quantitative PCR}

P4-CCR5 cells were infected with LAI-vsvG viruses (500 ng p24 antigen per $2 \times 10^{6}$ cells in $2 \mathrm{ml}$ ) for $2 \mathrm{~h}$ at $37^{\circ} \mathrm{C}$ and thereafter maintained at a concentration of $0.33 \times$ $10^{6}$ cells $/ \mathrm{ml}$. For each viral strain, a control of infected cells cultured in the presence of $5 \mu \mathrm{M}$ nevirapine, a nonnucleosidic RT inhibitor, was included. Total cellular DNA was extracted at given time points post-infection according to manufacturer's instruction (Qiagen) 2-LTR junctions were quantified by real-time PCR using a Realplex instrument (Eppendorf) with 5'AACTAGGGAACCCACTGCTTAAG3' forward primer, 5'TCCACAG ATCAAGGATATCTTGTC3' reverse primer and 5'FAM ACACTACTTGAAGCACTCAAGGC AAGCT TT TAMRA3' probe [58]. Pol gene copy number was determined with 5'TTTAGATGGA ATAGATAAG GCCCAA3' forward primer, 5'CAGCTGGCTAACTATTTCTTTTGCTA3' reverse primer and 5'FAM AATCACTAGCCATTGCTCTCCAATTAC TAMRA3'. Amplification was carried out for each reaction in $20 \mu \mathrm{l}$ with $300 \mathrm{nM}$ of each primer, $200 \mathrm{nM}$ of probe, $5 \mu \mathrm{l}$ of total-cell DNA and $10 \mu \mathrm{l}$ of $2 \mathrm{X}$ of FastStart Universal Probe Master (Roche). Assessment of integration by Alu-PCR was performed as previously described [59] at 24 h post-infection.

\section{Restriction enzyme analysis of intracellular viral DNA forms by Southern blotting}

MT4 cells were infected with HIV-1 $1_{\text {LAI }}$ vsvG viruses (500 ng p24 antigen per $10^{7}$ cells in $1 \mathrm{ml}$ ) for $2 \mathrm{~h}$ at $37^{\circ}$ $\mathrm{C}$ and thereafter maintained at a concentration of $0.5 \times$ $10^{6}$ cells $/ \mathrm{ml}$. At $48 \mathrm{~h}$ post-infection, total DNA was isolated by lysis in $10 \mathrm{mM}$ Tris, $10 \mathrm{mM}$ EDTA and $0.6 \%$ SDS. Samples were treated by RNase A $(100 \mu \mathrm{g} / \mathrm{ml})$ for $1 \mathrm{~h}$ at $37^{\circ} \mathrm{C}$, and proteinase $\mathrm{K}(100 \mu \mathrm{g} / \mathrm{ml})$ for $2 \mathrm{~h}$ at $55^{\circ}$ C. DNA was extracted by phenol chloroform and digested with $D p n I$ to remove contaminating bacterial plasmid DNA. Viral DNA was then digested with $M s c \mathrm{I}$ 
and XhoI, which create well-defined fragments on the basis of which the different intracellular forms of viral DNA can be distinguished [9]. Digested samples were then analysed by Southern blotting, using a probe that overlaps one of the two MscI sites in the HIV-1 genome [9]. Southern blots were quantified by phosphorimager (Molecular Dynamics) and the ImageQuant software.

\section{Single-cycle titration in P4-CCR5 and GHOST3 cells}

P4-CCR5 infections were carried out in triplicate in 96well plates $(10,000$ cells per well) with increasing doses of LAI or LAI-vsvG. $\beta$-Galactosidase activity was measured at $48 \mathrm{~h}$ postinfection by using a chemiluminescent $\beta$-galactosidase reporter gene assay according to manufacturer's instructions (Roche). GHOST3 infections were carried out in 6-well plates $(400,000$ cells per well) with increasing doses of LAI or NL43 Vpr-. The percentage of GFP+ cells was assessed $48 \mathrm{~h}$ p.i using flow cytometry (BD Calibur).

\section{Replication kinetics}

MT4 cells were infected with HIV-1 $1_{\mathrm{LAI}}$ and cPPT/CTS mutants in 96-well plates ( $1 \mathrm{ng}$ p24 antigen per $5 \times 10^{4}$ cells in $200 \mu \mathrm{l}$ ). Every 2 days for 24 days, $100 \mu \mathrm{l}$ of supernatant were collected and replaced by fresh medium. Viral concentration in supernatants was assessed by RT-assay. PBMCs, stimulated for 3 days with Concanavalin A $(5 \mu \mathrm{g} / \mathrm{ml})$, were infected with $\mathrm{HIV}_{\mathrm{LAI}}$ and cPPT/CTS mutants in 96-well plates (1 ng p24 antigen per $1 \times 10^{5}$ cells in $200 \mu \mathrm{l}$ ). Every $3-4$ days for 40 days, $100 \mu \mathrm{l}$ of supernatant were collected and replaced with fresh medium containing IL2 (final concentration $10 \mathrm{ng} /$ $\mathrm{ml})$. Viral concentration in supernatants was assessed by p24 ELISA (Perkin Elmer).

\section{Additional material}

Additional file 1: Figure S1: CPPT and CTS mutations do not affect viral production. The p24 concentrations $(\mathrm{ng} / \mathrm{ml})$ are shown for 3 to 6 independent preparations of each virus, both wild-type and VSV-G pseudotyped envelopes. The graph shows mean values +/- SEM. Oneway Anova analysis indicated that there is no statistically significant difference between any of the 16 mean values.

Additional file 2: Figure S2: GHOST cells were infected in parallel with viruses. GHOST cells were infected in parallel with viruses from the Hu et al., 2010 study (WT, mcPPT, DM) and our wild-type and mutant viruses (LAl, D, DM D). The percentage of GFP-positive cells was assessed at $48 \mathrm{~h}$ p.i using flow cytometry. Results are representative of three independent experiments.

\section{Acknowledgements and funding}

This work was funded by CONACyT (Consejo Nacional de Ciencia y Technologia), CNRS (Centre National de Recherche Scientifique), ANRS (Agence Nationale de Recherche sur le SIDA), FRM (Fondation pour la Recherche Médicale) and the Pasteur Institute.

\section{Author details}

${ }^{1}$ Molecular Virology and Vaccinology Unit, Department of Virology, Institut Pasteur, Paris, France. ${ }^{2}$ Centro de Investigacion en Enfermedades Infecciosas, Mexico Tlalpan, Mexico. ${ }^{3}$ Molecular Virology Laboratory, Institut de Génétique Humaine, Montpellier, France. ${ }^{4}$ Immunity and Cancer Unit, Institut Curie, Paris, France.

\section{Authors' contributions}

$\mathrm{Cl}$ generated the mutants and carried out Southern blotting experiments $M R$ and JF performed quantitative PCR. CI, MR, FDN, JF, RG, PS and NJA performed all other experiments. PC conceived the study. NJA participated in the design and coordination of the study, and wrote the manuscript. All authors read and approved the final manuscript.

\section{Competing interests}

The authors declare that they have no competing interests.

Received: 3 May 2011 Accepted: 10 November 2011 Published: 10 November 2011

\section{References}

1. Charneau P, Clavel F: A single-stranded gap in human immunodeficiency virus unintegrated linear DNA defined by a central copy of the polypurine tract. J Virol 1991, 65:2415-2421.

2. Harris JD, Scott JV, Traynor B, Brahic M, Stowring L, Ventura P, Haase AT, Peluso R: Visna virus DNA: discovery of a novel gapped structure. Virology 1981, 113:573-583.

3. Hungnes $\mathrm{O}$, Tjøtta $\mathrm{E}$, Grinde $\mathrm{B}$ : The plus strand is discontinuous in a subpopulation of unintegrated HIV-1 DNA. Arch Virol 1991, 116:133-141.

4. Stetor SR, Rausch JW, Guo MJ, Burnham JP, Boone LR, Waring MJ, Le Grice SF: Characterization of (+) strand initiation and termination sequences located at the center of the equine infectious anemia virus genome. Biochemistry 1999, 38:3656-3667.

5. Whitwam T, Peretz M, Poeschla E: Identification of a central DNA flap in feline immunodeficiency virus. J Virol 2001, 75:9407-9414.

6. Charneau P, Mirambeau G, Roux P, Paulous S, Buc H, Clavel F: HIV-1 reverse transcription $A$ termination step at the center of the genome. $J \mathrm{Mol} B \mathrm{BiO}$ 1994, 241:651-662.

7. Charneau P, Alizon M, Clavel F: A second origin of DNA plus-strand synthesis is required for optimal human immunodeficiency virus replication. J Virol 1992, 66:2814-2820.

8. Hungnes $\mathrm{O}$, Tjøtta $\mathrm{E}$, Grinde B: Mutations in the central polypurine tract of HIV-1 result in delayed replication. Virology 1992, 190:440-442.

9. Zennou V, Petit C, Guetard D, Nerhbass U, Montagnier L, Charneau P: HIV-1 genome nuclear import is mediated by a central DNA flap. Cell 2000, 101:173-185.

10. Arhel N, Munier S, Souque P, Mollier K, Charneau P: Nuclear import defect of human immunodeficiency virus type 1 DNA flap mutants is not dependent on the viral strain or target cell type. J Virol 2006, 80:10262-10269.

11. De Rijck J, Debyser Z: The central DNA flap of the human immunodeficiency virus type 1 is important for viral replication. Biochem Biophys Res Commun 2006, 349:1100-1110.

12. Arhel NJ, Souquere-Besse S, Charneau P: Wild-type and central DNA flap defective HIV-1 lentiviral vector genomes: intracellular visualization at ultrastructural resolution levels. Retrovirology 2006, 3:38.

13. Follenzi A, Ailles LE, Bakovic S, Geuna M, Naldini L: Gene transfer by lentiviral vectors is limited by nuclear translocation and rescued by HIV1 pol sequences. Nat Genet 2000, 25:217-222.

14. Wurtzer S, Goubard A, Mammano F, Saragosti S, Lecossier D, Hance AJ, Clavel F: Functional central polypurine tract provides downstream protection of the human immunodeficiency virus type 1 genome from editing by APOBEC3G and APOBEC3B. J Virol 2006, 80:3679-3683.

15. Yu Q, König R, Pillai S, Chiles K, Kearney M, Palmer S, Richman D, Coffin JM, Landau NR: Single-strand specificity of APOBEC3G accounts for minusstrand deamination of the HIV genome. Nat Struct Mol Biol 2004, 11:435-442.

16. Hu C, Saenz DT, Fadel HJ, Walker W, Peretz M, Poeschla EM: The HIV-1 central polypurine tract functions as a second line of defense against APOBEC3G/F. J Virol 2010, 84:11981-11993. 
17. Arhel NJ, Souquere-Besse $S$, Munier $S$, Souque P, Guadagnini $S$, Rutherford S, Prévost MC, Allen TD, Charneau P: HIV-1 DNA Flap formation promotes uncoating of the pre-integration complex at the nuclear pore. EMBO J 2007, 26:3025-3037.

18. Baekelandt V, Claeys A, Eggermont K, Lauwers E, De Strooper B, Nuttin B, Debyser Z: Characterization of lentiviral vector-mediated gene transfer in adult mouse brain. Hum Gene Ther 2002, 13:841-853.

19. Barry SC, Harder B, Brzezinski M, Flint LY, Seppen J, Osborne WR: Lentivirus vectors encoding both central polypurine tract and posttranscriptional regulatory element provide enhanced transduction and transgene expression. Hum Gene Ther 2001, 12:1103-1108.

20. Breckpot K, Dullaers M, Bonehill A, van Meirvenne S, Heirman C, de Greef C, van der Bruggen $P$, Thielemans $K$ : Lentivirally transduced dendritic cells as a tool for cancer immunotherapy. J Gene Med 2003, 5:654-667.

21. Dardalhon V, Herpers B, Noraz N, Pflumio F, Guetard D, Leveau C, DubartKupperschmitt A, Charneau P, Taylor N: Lentivirus-mediated gene transfer in primary T cells is enhanced by a central DNA flap. Gene Ther 2001, 8:190-198

22. De Rijck J, Van Maele B, Debyser Z: Positional effects of the central DNA flap in HIV-1-derived lentiviral vectors. Biochem Biophys Res Commun 2005, 328:987-994.

23. Demaison C, Parsley K, Brouns G, Scherr M, Battmer K, Kinnon C, Grez M, Thrasher AJ: High-level transduction and gene expression in hematopoietic repopulating cells using a human immunodeficiency virus type 1-based lentiviral vector containing an internal spleen focus forming virus promoter. Hum Gene Ther 2002, 13:803-813.

24. Giannini C, Morosan S, Tralhao JG, Guidotti JE, Battaglia S, Mollier K, Hannoun L, Kremsdorf D, Gilgenkrantz H, Charneau P: A highly efficient, stable, and rapid approach for ex vivo human liver gene therapy via a FLAP lentiviral vector. Hepatology 2003, 38:114-122.

25. Gropp M, Itsykson P, Singer O, Ben-Hur T, Reinhartz E, Galun E, Reubinoff BE: Stable genetic modification of human embryonic stem cells by lentiviral vectors. Mol Ther 2003, 7:281-287.

26. Manganini $M$, Serafini $M$, Bambacioni F, Casati $C$, Erba E, Follenzi $A$, Naldini L, Bernasconi S, Gaipa G, Rambaldi A, Biondi A, Golay J, Introna M: A human immunodeficiency virus type 1 pol gene-derived sequence CPPT/CTS) increases the efficiency of transduction of human nondividing monocytes and T lymphocytes by lentiviral vectors. Hum Gene Ther 2002, 13:1793-1807

27. Nguyen TH, Oberholzer J, Birraux J, Majno P, Morel P, Trono D: Highly efficient lentiviral vector-mediated transduction of nondividing, fully reimplantable primary hepatocytes. Mol Ther 2002, 6:199-209.

28. Park F, Kay MA: Modified HIV-1 based lentiviral vectors have an effect on viral transduction efficiency and gene expression in vitro and in vivo. Mol Ther 2001, 4:164-173.

29. Riviere $L$, Darlix $J$, Cimarelli $A$ : Analysis of the viral elements required in the nuclear import of HIV-1 DNA. J Virol 2010, 84:729-739.

30. Seppen J, Rijnberg M, Cooreman MP, Oude Elferink RP: Lentiviral vectors for efficient transduction of isolated primary quiescent hepatocytes. $J$ Hepatol 2002, 36:459-465.

31. Sirven A, Pflumio F, Zennou V, Titeux M, Vainchenker W, Coulombel L, Dubart-Kupperschmitt A, Charneau P: The human immunodeficiency virus type-1 central DNA flap is a crucial determinant for lentiviral vector nuclear import and gene transduction of human hematopoietic stem cells. Blood 2000, 96:4103-4110.

32. VandenDriessche T, Thorrez L, Naldini L, Follenzi A, Moons L, Berneman Z, Collen D, Chuah MK: Lentiviral vectors containing the human immunodeficiency virus type-1 central polypurine tract can efficiently transduce nondividing hepatocytes and antigen-presenting cells in vivo. Blood 2002, 100:813-822.

33. Van Maele B, De Rijck J, De Clercq E, Debyser Z: Impact of the central polypurine tract on the kinetics of human immunodeficiency virus type 1 vector transduction. J Virol 2003, 77:4685-4694.

34. Zennou V, Serguera C, Sarkis C, Colin P, Perret E, Mallet J, Charneau P: The HIV-1 DNA flap stimulates HIV vector-mediated cell transduction in the brain. Nat Biotechnol 2001, 19:446-450.

35. Dvorin JD, Bell P, Maul GG, Yamashita M, Emerman M, Malim MH: Reassessment of the roles of integrase and the central DNA flap in human immunodeficiency virus type 1 nuclear import. J Virol 2002, 76:12087-12096.
36. Limon A, Nakajima N, Lu R, Ghory HZ, Engelman A: Wild-type levels of nuclear localization and human immunodeficiency virus type 1 replication in the absence of the central DNA flap. J Virol 2002, 76:12078-12086

37. Marsden MD, Zack JA: Human immunodeficiency virus bearing a disrupted central DNA flap is pathogenic in vivo. J Virol 2007, 81:6146-6150.

38. Yamashita M, Emerman M: The cell cycle independence of HIV infections is not determined by known karyophilic viral elements. PLOS Pathog 2005, 1:e18.

39. Ao Z, Yao X, Cohen EA: Assessment of the role of the central DNA flap in human immunodeficiency virus type 1 replication by using a singlecycle replication system. J Virol 2004, 78:3170-3177.

40. Hare S, Di Nunzio F, Labeja A, Wang J, Engelman A, Cherepanov P: Structural basis for functional tetramerization of lentiviral integrase. PLOS Pathog 2009, 5:e1000515.

41. Mandal D, Prasad VR: Analysis of 2-LTR circle junctions of viral DNA in infected cells. Methods Mol Biol 2009, 485:73-85.

42. Shank PR, Varmus HE: Virus-specific DNA in the cytoplasm of avian sarcoma virus-infected cells is a precursor to covalently closed circular viral DNA in the nucleus. J Virol 1978, 25:104-114.

43. Kim SY, Byrn R, Groopman J, Baltimore D: Temporal aspects of DNA and RNA synthesis during human immunodeficiency virus infection: evidence for differential gene expression. J Virol 1989, 63:3708-3713.

44. Farnet $C M$, Haseltine WA: Integration of human immunodeficiency virus type 1 DNA in vitro. Proc Natl Acad Sci USA 1990, 87:4164-4168.

45. Farnet $C M$, Haseltine WA: Circularization of human immunodeficiency virus type 1 DNA in vitro. J Virol 1991, 65:6942-6952.

46. Bouyac-Bertoia M, Dvorin JD, Fouchier RA, Jenkins Y, Meyer BE, Wu LI, Emerman M, Malim MH: HIV-1 infection requires a functional integrase NLS. Mol Cell 2001, 7:1025-1035.

47. Katz RA, Greger JG, Boimel P, Skalka AM: Human immunodeficiency virus type 1 DNA nuclear import and integration are mitosis independent in cycling cells. J Virol 2003, 77:13412-13417.

48. König R, Zhou Y, Elleder D, Diamond TL, Bonamy GM, Irelan JT, Chiang CY, Tu BP, De Jesus PD, Lilley CE, Seidel S, Opaluch AM, Caldwell JS, Weitzman MD, Kuhen KL, Bandyopadhyay S, Ideker T, Orth AP, Miraglia LJ, Bushman FD, Young JA, Chanda SK: Global analysis of host-pathogen interactions that regulate early-stage HIV-1 replication. Cell 2008, 135:49-60.

49. Fuller BG: Self-organization of intracellular gradients during mitosis. Cell Div 2010, 5:5.

50. Kalab P, Heald R: The RanGTP gradient - a GPS for the mitotic spindle. $J$ Cell Sci 2008, 121:1577-1586.

51. Christ F, Thys W, De Rijck J, Gijsbers R, Albanese A, Arosio D, Emiliani S, Rain JC, Benarous R, Cereseto A, Debyser Z: Transportin-SR2 imports HIV into the nucleus. Curr Biol 2008, 18:1192-1202.

52. Thys W, De Houwer S, Demeulemeester J, Taltynov O, Vancraenenbroeck R, Gérard M, De Rijck J, Gijsbers R, Christ F, Debyser Z: Interplay between HIV Entry and Transportin-SR2 Dependency. Retrovirology 2011, 8:7.

53. Matreyek KA, Engelman A: The Requirement for Nucleoporin NUP153 During Human Immunodeficiency Virus Type 1 Infection is Determined by the Viral Capsid. J Virol 2011.

54. Harada S, Koyanagi Y, Yamamoto N: Infection of human T-lymphotropic virus type-I (HTLV-I)-bearing MT-4 cells with HTLV-III (AIDS virus): chronological studies of early events. Virology 1985, 146:272-281.

55. Barré-Sinoussi F, Chermann JC, Rey F, Nugeyre MT, Chamaret S, Gruest J, Dauguet C, Axler-Blin C, Vézinet-Brun F, Rouzioux C, Rozenbaum W, Montagnier L: Isolation of a T-lymphotropic retrovirus from a patient at risk for acquired immune deficiency syndrome (AIDS). Science 1983, 220:868-871.

56. Borman AM, Quillent C, Charneau P, Dauguet C, Clavel F: Human immunodeficiency virus type 1 Vif- mutant particles from restrictive cells: role of Vif in correct particle assembly and infectivity. J Virol 1995, 69:2058-2067.

57. Yee JK, Miyanohara A, LaPorte P, Bouic K, Burns JC, Friedmann T: A general method for the generation of high-titer, pantropic retroviral vectors: highly efficient infection of primary hepatocytes. Proc Natl Acad Sci USA 1994, 91:9564-9568.

58. Butler SL, Hansen MS, Bushman FD: A quantitative assay for HIV DNA integration in vivo. Nat Med 2001, 7:631-634. 
59. Brussel A, Sonigo P: Analysis of early human immunodeficiency virus type 1 DNA synthesis by use of a new sensitive assay for quantifying integrated provirus. J Virol 2003, 77:10119-10124.

doi:10.1186/1742-4690-8-92

Cite this article as: Iglesias et al:: Residual HIV-1 DNA Flap-independent nuclear import of CPPT/CTS double mutant viruses does not support spreading infection. Retrovirology 2011 8:92.

Submit your next manuscript to BioMed Central and take full advantage of:

- Convenient online submission

- Thorough peer review

- No space constraints or color figure charges

- Immediate publication on acceptance

- Inclusion in PubMed, CAS, Scopus and Google Scholar

- Research which is freely available for redistribution

Submit your manuscript at www.biomedcentral.com/submit 